\title{
Article \\ Effect of Spatial-Temporal Light Competition on Cotton Yield and Yield Distribution
}

\author{
Qingru Wang ${ }^{1,2}$, Huanxuan Chen 1,2 ${ }^{\mathbb{D}}$, Yingchun Han ${ }^{2}$, Fangfang Xing ${ }^{2}$, Zhanbiao Wang 1,2, Lu Feng ${ }^{1,2}$, \\ Guoping Wang ${ }^{2}$, Beifang Yang ${ }^{2}$, Yaping Lei ${ }^{2}$, Shiwu Xiong ${ }^{2}$, Xiaofei Li ${ }^{2}$, Minghua Xin ${ }^{2}$, Wenli Du ${ }^{2}$ \\ and Yabing $\mathrm{Li}^{1,2, *}$
}

1 Zhengzhou Research Base, State Key Laboratory of Cotton Biology, School of Agricultural Sciences, Zhengzhou University, Zhengzhou 450001, China; wqrr220@163.com (Q.W.); chenhuanxuan123@163.com (H.C.); wang_zhanbiao@126.com (Z.W.); fenglucri@126.com (L.F.)

2 State Key Laboratory of Cotton Biology, Institute of Cotton Research of Chinese Academy of Agricultural Sciences, Anyang 455000, China; hyccky@163.com (Y.H.); xingyue530@163.com (F.X.); Zmswgp@126.com (G.W.); yangbf8002@163.com (B.Y.); lei200279@163.com (Y.L.); 18703673670@163.com (S.X.); lixiaofei01@caas.cn (X.L.); xinminghua985@126.com (M.X.); w1233216917@163.com (W.D.)

* Correspondence: liyabing@caas.cn; Tel.: +86-0372-256-2293

Citation: Wang, Q.; Chen, H.; Han, Y.; Xing, F.; Wang, Z.; Feng, L.; Wang, G.; Yang, B.; Lei, Y.; Xiong, S.; et al. Effect of Spatial-Temporal Light Competition on Cotton Yield and Yield Distribution. Agronomy 2021, 11, 2346. https://doi.org/10.3390/ agronomy11112346

Academic Editor: Jane K. Dever

Received: 18 September 2021 Accepted: 16 November 2021 Published: 19 November 2021

Publisher's Note: MDPI stays neutral with regard to jurisdictional claims in published maps and institutional affiliations.

Copyright: (c) 2021 by the authors Licensee MDPI, Basel, Switzerland. This article is an open access article distributed under the terms and conditions of the Creative Commons Attribution (CC BY) license (https:// creativecommons.org/licenses/by/ $4.0 /)$.

\begin{abstract}
The photosynthetically active radiation (PAR) of crop canopy is highly related to yield formation, but how it relates to yield and yield distribution is not well understood. The focus of this study was to explore the relationship between light competition under different densities and yield distributions of cotton. The experiment was conducted in 2019 and 2020 at the Cotton Research Institute of the Chinese Academy of Agricultural Sciences in Anyang city, Henan Province, China. A randomized block design was employed, with a total of three repeats. Each repeat had six density treatments: D1: 15,000; D2: 33,000; D3: 51,000; D4: 69,000; D5: 87,000; and D6: 105,000 plants·ha ${ }^{-1}$. As predicted, the results showed that the canopy light interception, leaf area index, plant height, and biomass of high-density cotton were higher than those of low-density cotton. The aboveground biomass produced by D6 was the highest, and was 12.9, 19.5, 25.4, 46.3, and 69.2\% higher in 2019 and 14.3, 19.9, 32.5, 53.7, and 109.9\% higher in 2020 than D5, D4, D3, D2, and D1, respectively. Leaf area, plant height, biomass, boll number, and boll weight were significantly correlated with the light interception rate. D5 (87,000 plants.ha $\left.{ }^{-1}\right)$ had a higher light interception rate and the highest yield. The highest lint yields produced by D5 were 1673.5 and $1375.4 \mathrm{~kg} \cdot \mathrm{ha}^{-1}$ in two years, and was $3.2,4.3$, 5.6, 9.7, and 24.7\% higher in 2019, and 6.8, 10.6, 13.5, 21.5, and 34.4\% higher in 2020 than D6, D4, D3, D2, and D1, respectively. The boll retention of the lower fruit branch under D5 reached 0.51 and 0.57 in two years, respectively. The shedding rate of the upper fruit branch decreased with the increase in cotton density in two years. The boll retention rate and shedding rate in the lower part of cotton plants were most closely related to light interception, with $\mathrm{R}^{2}$ values of 0.91 and 0.96 , respectively. Our study shows cotton yield could be improved through higher light interception by optimizing planting density and canopy structure.
\end{abstract}

Keywords: light interception; plant density; yield distribution

\section{Introduction}

The environmental resources needed for plant growth, development, and reproduction are roughly the same [1]. Each individual in the group cannot own environmental factors and must share them with others. Craine [2] defined resource competition as "a process in which two or more individuals obtained potentially common and limited resources in different ways". Light resources are the most important energy source for plant growth, and the total amount of light resources per unit land area available for plants is limited. Plants compete for light resources, causing light competition among plants [3]. 
Cotton (Gossypium hirsutum L.) is not only a cash crop in China [4], but also an important strategic material related to the national economy and people's livelihood [5]. It involves the financial revenue of more than 200 cotton production bases and counties, as well as the normal operation of cotton processing, circulation, clothing industry, and import and export trade [6]. In recent years, cotton planting costs have increased in China, and the planting benefits have gradually decreased [7]. At the same time, with the increase in population, the arable land area for cotton production has gradually decreased, and cotton grain competition has become increasingly significant [8], resulting in a downward trend of cotton production overall. Cotton production is a group production under field conditions, and the yield per unit area mainly depends on the photosynthetic capacity of the population per unit area [9]. Therefore, the establishment of a population structure with high light efficiency is a core issue in the cultivation of high-quality and high-yield cotton. Understanding the competition for light energy of the population, improving the photosynthetic performance of the population, and improving the utilization rate of light energy are critical for realizing high-quality and high-yield cotton.

Competition among plant species for resources in the same niches involves density $[10,11]$. If the density is high, the competition is strong, and if the density is low, the competition is weak [12]. When competition occurs at the individual level of the plant, to ensure their own survival needs, plants will reasonably regulate the distribution of their own photosynthates, so the organs will be affected, and the organ biomass will change accordingly [13]. At the population level, when the density increases beyond a certain threshold and the competition intensity reaches the maximum, the crop population will exhibit a self-thinning phenomenon [14], which will affect the total plant biomass and yield [15]. Zhang found that increasing the planting density before the full boll stage increased the leaf area index, thus increasing the light interception rate of the canopy and the photosynthesis of the cotton population. However, after the full boll stage, too high a density will lead to a rapid decrease in the leaf photosynthetic rate, which is not conducive to the production and transport of photosynthetic substances, thus reducing the boll weight [16]. Yao showed that the canopy structure and leaf photosynthetic characteristics changed with the narrow row spacing of cotton, and its yield was affected by the photosynthetic efficiency [17]. Changing the crop planting density is a time-tested agronomic technique that can increase crop yield and profitability [18].

Generally, light interception varies with the developmental stage of crops, and dry matter production is positively correlated with light interception [19]. The photosynthate distribution in plants is usually affected by biological factors (such as competition) and environmental factors (light, water, nutrition) [20]. Competition for aboveground light resources will affect the quantity and distribution characteristics of available resources, which may affect the biomass allocation of plant organs [21]. However, how light interception affects the yield distribution of cotton plants has not been determined.

The purpose of this experiment was to study the relationship between light energy competition and the yield distribution of a cotton population with different densities. The main purpose was to explore (1) the changes and differences in canopy light interception of cotton individuals and the population under different densities during the whole growth period, (2) the changes in the leaf area index and aboveground biomass of different cotton individuals and the population with canopy light interception, and in particular, (3) the relationship between canopy light interception and plant boll distribution of different cotton populations.

\section{Materials and Methods}

\subsection{Experimental Site}

The experiment was carried out in 2019 and 2020 in the eastern field of the Cotton Research Institute of the Chinese Academy of Agricultural Sciences in Anyang city, Henan Province $\left(36^{\circ} 06^{\prime} \mathrm{N}, 114^{\circ} 21^{\prime} \mathrm{E}\right)$. Meteorological data were obtained from the weather station at the experimental site (Table 1 ). The monthly average temperatures for the two years 
during the growing seasons were 22 and $21^{\circ} \mathrm{C}$, and the precipitation was 392 and $318 \mathrm{~mm}$, respectively. The average temperature in 2019 was slightly higher than that in 2020, and the precipitation in 2019 was lower than that in 2020. The monthly average PAR in 2019 was almost higher than that in 2020, and the total sunshine hours in 2019 and 2020 were 1548 and $1535 \mathrm{~h}$, respectively.

Table 1. Meteorological information of the cotton growth period in the experimental site.

\begin{tabular}{ccccccccc}
\hline Meteorological Data & Year & April & May & June & July & August & September & October \\
\hline \multirow{2}{*}{ Precipitation $(\mathrm{mm})$} & 2019 & 70.4 & 5.0 & 55.4 & 42.0 & 116.1 & 51.3 & 51.5 \\
& 2020 & 28.8 & 39.5 & 50.4 & 29.2 & 156.1 & 3.6 & 9.9 \\
\hline \multirow{2}{*}{ Temperature $\left({ }^{\circ} \mathrm{C}\right)$} & 2019 & 14.4 & 22.0 & 27.9 & 28.5 & 25.5 & 22.0 & 15.4 \\
& 2020 & 14.2 & 22.2 & 26.2 & 26.0 & 26.0 & 21.9 & 14.4 \\
\hline \multirow{2}{*}{ Sunshine hours (h) } & 2019 & 193.6 & 297.7 & 256.7 & 260.2 & 186.6 & 213.7 & 139.9 \\
& 2020 & 284.4 & 294.3 & 206.5 & 204.4 & 196.4 & 226.3 & 123.1 \\
\hline Daily PAR & 2019 & 315.3 & 497.8 & 483.4 & 455.5 & 377.6 & 319.8 & 211.5 \\
$\left(\mu \mathrm{mol} \cdot \mathrm{m}^{-2} \cdot \mathrm{s}^{-1}\right)$ & 2020 & 405.6 & 467.6 & 413.7 & 411.4 & 360.5 & 364.9 & 198.2 \\
\hline
\end{tabular}

\subsection{Experimental Design}

The experiment was conducted in a randomized block design with 3 repeats (Figure 1). The cotton variety tested was SCRC28, which has a loose plant type, medium maturity, steady growth throughout the growth period, and has been sown in the experimental base all year round. The six density treatments were D1: 15,000, D2: 33,000, D3: 51,000, D4: 69,000, D5: 87,000, and D6: 105,000 plants $\cdot \mathrm{ha}^{-1}$. The experimental plot was 10 rows, the row spacing was $0.8 \mathrm{~m}$, and the plot area was $64 \mathrm{~m}^{2}$. The seeds were sown on 17 and 18 April in 2019 and 2020, respectively. The sowing method was manual on demand, and the seedlings were manually determined at the two-leaf stage after emergence. Before sowing and applying fertilizer, the experimental plot was irrigated with foot entropy water, which means no trench stalks were made in the field, and they were allowed to flow on the ground, and the amount of irrigation was approximately $290 \mathrm{~m}^{3} \cdot \mathrm{ha}^{-1}$. Before sowing, basic fertilizer was applied to the field (N $225 \mathrm{~kg} \cdot \mathrm{ha}^{-1}, \mathrm{P}_{2} \mathrm{O}_{5} 150 \mathrm{~kg} \cdot \mathrm{ha}^{-1}$, and $\mathrm{K}_{2} \mathrm{O} 225 \mathrm{~kg} \cdot \mathrm{ha}^{-1}$ ), and topdressing was applied at the flowering and boll development stage ( $\mathrm{N} 273 \mathrm{~kg} \cdot \mathrm{ha}^{-1}$, $\mathrm{P}_{2} \mathrm{O}_{5} 169 \mathrm{~kg} \cdot \mathrm{ha}^{-1}$, and $\left.\mathrm{K}_{2} \mathrm{O} 169 \mathrm{~kg} \cdot \mathrm{ha}^{-1}\right)$. In the middle stage of cotton growth, mechanical weeding and spraying of pesticides, plant growth regulators, and chemical control methods were used to control diseases and insect pests.

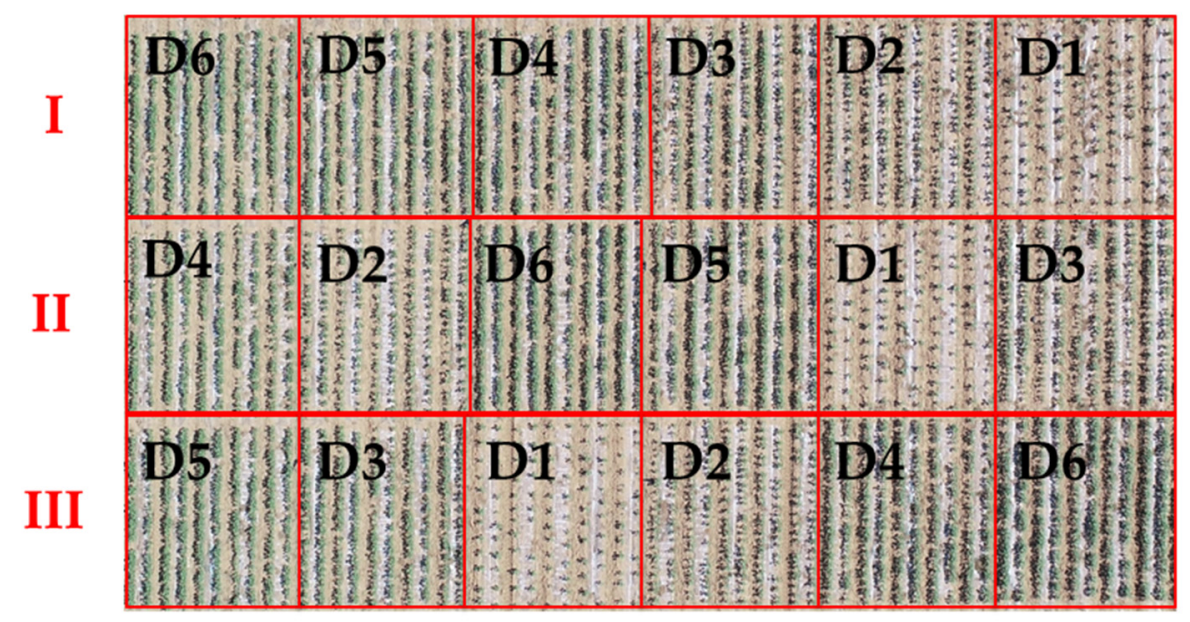

Figure 1. The graphic illustration of sowing planting patterns in 2019 and 2020. 


\subsection{Data Collection}

\subsubsection{Investigation of the Cotton Growth Period}

The growth of cotton was investigated every three days after cotton emergence, and the time when the cotton population entered the squaring stage ( $50 \%$ of cotton plants showed squares approximately $3 \mathrm{~mm}$ in diameter), flowering stage ( $50 \%$ of cotton plants produced the first white flower), and boll opening stage ( $50 \%$ of cotton plants began to show opened bolls) was recorded in 2019 and 2020. The results of the survey are shown in Table 2.

Table 2. Cotton growth stages with different planting densities in 2019 and 2020.

\begin{tabular}{|c|c|c|c|c|c|c|}
\hline Cultivar & Treatment & Emergence/DAE ${ }^{1}$ & Seedling/DAE & Squaring/DAE & Flowering/DAE & Boll Opening/DAE \\
\hline \multirow{14}{*}{ SCRC28 } & \multicolumn{6}{|c|}{ Year 2019} \\
\hline & D1 & $4-28 / 0$ & $5-20 / 22$ & $5-28 / 30$ & $6-24 / 57$ & $8-14 / 108$ \\
\hline & D2 & $4-28 / 0$ & $5-20 / 22$ & $5-28 / 30$ & $6-24 / 57$ & $8-15 / 109$ \\
\hline & D3 & $4-28 / 0$ & $5-20 / 22$ & $5-30 / 32$ & $6-24 / 57$ & $8-15 / 109$ \\
\hline & $\mathrm{D} 4$ & $4-28 / 0$ & $5-20 / 22$ & $5-30 / 32$ & $6-24 / 57$ & $8-16 / 110$ \\
\hline & D5 & $4-28 / 0$ & $5-20 / 22$ & $5-31 / 33$ & $6-26 / 59$ & $8-17 / 111$ \\
\hline & D6 & $4-28 / 0$ & $5-20 / 22$ & $5-31 / 33$ & $6-26 / 59$ & $8-19 / 113$ \\
\hline & \multicolumn{6}{|c|}{ Year 2020} \\
\hline & D1 & $4-27 / 0$ & $5-15 / 18$ & $5-31 / 34$ & $6-28 / 62$ & $8-21 / 116$ \\
\hline & $\mathrm{D} 2$ & $4-27 / 0$ & $5-15 / 18$ & $5-30 / 33$ & $6-27 / 61$ & $8-22 / 117$ \\
\hline & D3 & $4-27 / 0$ & $5-15 / 18$ & $5-29 / 32$ & $6-27 / 61$ & $8-21 / 116$ \\
\hline & D4 & $4-27 / 0$ & $5-15 / 18$ & $6-1 / 35$ & $6-27 / 61$ & $8-22 / 117$ \\
\hline & D5 & $4-27 / 0$ & $5-15 / 18$ & $6-1 / 35$ & $6-28 / 62$ & $8-21 / 116$ \\
\hline & D6 & $4-27 / 0$ & $5-15 / 18$ & $5-29 / 32$ & $6-26 / 60$ & $8-22 / 117$ \\
\hline
\end{tabular}

${ }^{1}$ DAE: Days after emergence. D1: 15,000, D2: 33,000, D3: 51,000, D4: 69,000, D5: 87,000, D6: 105,000 plants.ha ${ }^{-1}$.

\subsubsection{Light Interception}

Starting from the cotton seedling stage, after each sampling, two rows of cotton with uniform and representative growth in each plot were selected for measurement during sunny and cloudless weather from 10:00 in the morning, with one repeat each time. The spatial grid method was used in this experiment (Supplementary Materials Figure S1), and the $80 \mathrm{~cm}$ horizontal distance between two rows of cotton was equally divided into four equal parts, which were used as measuring points at $0,20,40,60$, and $80 \mathrm{~cm}$, respectively. In the vertical position, perpendicular to the ground, the $20 \mathrm{~cm}$ layer was divided into several layers so that a spatial grid perpendicular to the direction of the cotton row was obtained. The light interception of the cotton canopy was measured by a 1-m-long portable linear light quantum sensor (LI-191SA, LI-COR, Lincoln, NE, USA), and the data were recorded by a data collector (LI-1400, LI-COR, Lincoln, NE, USA). The measurement was carried out in order at each point, andthe sensor was placed in the parallel direction, the intercepted PAR intensity was measured with sensor facing up, and then the reflected PAR intensity was measured with the sensor facing down. At the same time, a sensor was placed $20 \mathrm{~cm}$ above the canopy, and the total intensity of the incident PAR was automatically recorded in real time every $5 \mathrm{~s}$.

According to the calculation method of Tang [22], the PAR interception (iPAR), PAR reflectance (rPAR), and PAR transmittance (tPAR) of each part of the cotton canopy were obtained (Supplementary Materials Formulas (S1)-(S3)).

According to Zhi's research [23], under the planting density of 60,000 plants per hectare, the light reflectivity of the cotton population was only $3-5 \%$, which had little effect on the growth and development of cotton. Therefore, the effect of reflected light on the growth and development of cotton was ignored in this experiment, so Supplementary materials Formula S3 was simplified as follows:

$$
\operatorname{iPAR}=1-\text { tPAR }
$$


The coordinate system was created in the vertical direction of the test area, and the positions of the tested points and the points to be measured in the test area were used to create Grid $(i, j)$ files, where $i$ and $j$ represent the abscissa and ordinate of the cross-sectional area of the test area, respectively.

The cumulative interception rate and transmittance in the whole canopy was calculated by Surfer software (Golden Software Inc., Golden, CO, USA) using the extended Simpson's $3 / 8$ rule. The formula was as follows [24]:

$$
\begin{gathered}
A_{i}=\frac{3 \Delta X}{8}\left(G_{i, 1}+3 G_{i, 2}+3 G_{i, 3}+2 G_{i, 4}+\cdots+2 G_{i, n c o l-1}+G_{i, n c o l}\right) \\
\mathrm{V} \approx \frac{3 \Delta y}{8}\left(A_{1}+3 A_{2}+3 A_{3}+2 A_{4}+\cdots+2 A_{n c o l-1}+A_{n c o l}\right)
\end{gathered}
$$

Among them, $[1,3,3,2, \ldots]$ is the coefficient vector in Formulas (2) and (3), $\mathrm{G}_{i, j}$ is the depth of the grid points of row $i$ and row $j$, and $\Delta X$ and $\Delta y$ are the column spacing and row spacing of the grid data file, respectively. $A_{i}$ is the $i$ th cross-sectional area, and $\mathrm{V}$ is the total amount of light on the specific cross-section measured.

The test area in the canopy of the whole population was longitudinally divided into three parts, and the average cross-sectional area on both sides was taken as the crosssectional area of a single plant and then calculated as the light interception of a single plant by the extension of Simpson's 3/8 rule.

To study the relationship between light interception in different regions and the boll retention rate and shedding rate in corresponding regions, the whole cotton canopy was vertically divided into the lower region, middle region, and upper region and horizontally divided into the inner region near the main stem and the peripheral area far from the main stem (Supplementary Materials Figure S2).

\subsubsection{Leaf Area and Biomass}

Samples were taken every 15 days from the seeding stage at 30, 45, 59, 73, 88, 99, 115, 128, and 145 DAE in 2019 and at 28, 43, 58, 73, 87, 98, 113, and 128 DAE in 2020, with three repeats each time. Two representative plants with the same growth were selected in each plot, and the parts above the cotyledon nodes were separated according to leaves, stems, and reproductive organs (squares, flowers, bolls, catkins). The leaves were tiled and photographed by scanners (Phantom 9800xl, MICRTEK, Shanghai, China). Then, Image-Pro Plus (Media Cybernetics, Rockville, MD, USA) was used to calculate the leaf area and the leaf area index (leaf area index, LAI) according to the planting density. The metabolism of the separated fresh samples was stopped at $105^{\circ} \mathrm{C}$, and the samples were put into an oven at $80^{\circ} \mathrm{C}$. After drying to a constant weight, the dry matter mass of each part was measured. The cumulative cotton biomass in the growing season was calculated. The cumulative biomass growth was based on the logistic growth curve, and the formula was as follows [25]:

$$
\mathrm{Y}=\frac{\mathrm{A}}{1+\mathrm{be}^{-\mathrm{kt}}}
$$

In the formula, $\mathrm{Y}$ is the cotton plant biomass, $\mathrm{A}$ is the theoretical maximum biomass, $\mathrm{t}$ is the days after emergence (DAE), and $\mathrm{b}$ and $\mathrm{k}$ are constants.

The following formulas (Supplementary Materials Formulas (S4)-(S9)) can be concluded from Formula (4).

\subsubsection{Plant Height}

The two plants selected during sampling were measured with a ruler, and the position from the cotyledon node to the growth point was the height of a single plant. The average height was calculated using data from all measured plants in each treatment. 


\subsubsection{Yield}

The primary, secondary, and tertiary flowers and green bolls were collected in each experimental plot; the seed cotton yield and lint yield were calculated; and the lint percentage (100 bolls) was calculated by dividing the lint yield by the seed cotton yield.

\subsubsection{Data Processing and Analysis}

Stata 14.0 (Stata Corporation, College Station, TX, USA) was used to process the data in batches, and Microsoft Excel 2019 (Microsoft, Bothell, WA, USA) and Origin 2018 (OriginLab Corporation, Northampton, MA, USA) were used to analyze and draw cotton growth-related parameters (LAI, PAR interception rate, biomass, etc.). Image-Pro Plus 6.0 was used to calculate the LAI, Stata 14.0 and Surfer 17 (Golden Software Inc., Golden, CO, USA) were used to process and analyze the light interception data, and SPSS 25.0 (SPSS Inc., Chicago, IL, USA) statistical software was used to analyze the significance. The English abbreviations used in this experiment are mentioned in Supplementary Materials Table S1.

\section{Results}

3.1. iPAR, Leaf Area, Plant Height, and Biomass of Different Densities Change with Time

\subsubsection{Light Interception}

The results for the light interception of a single plant are shown in Figure 2, and the results for the light interception of the population are shown in Figure 3.
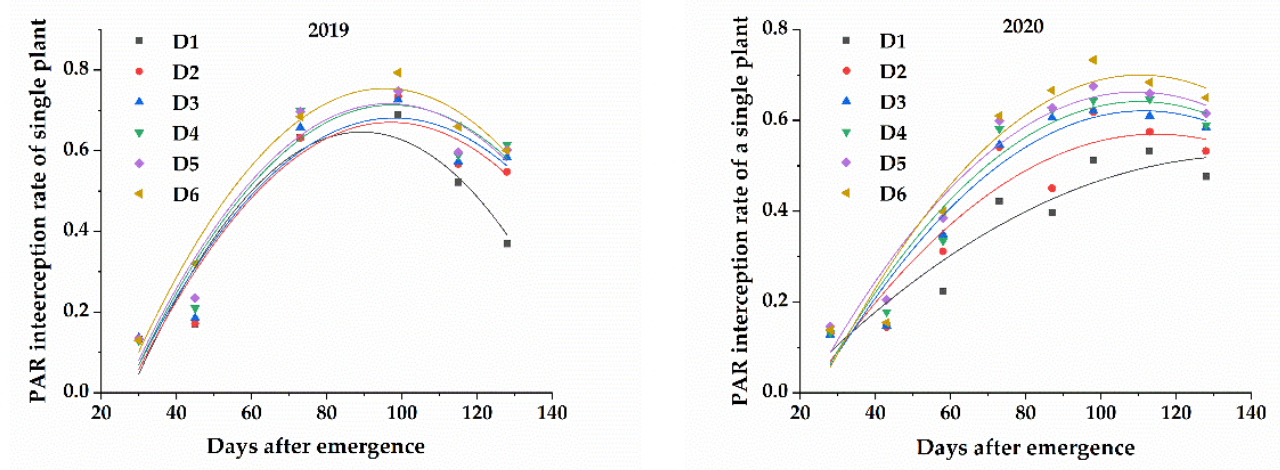

Figure 2. PAR interception rate of single plant at different planting densities in 2019 and 2020.
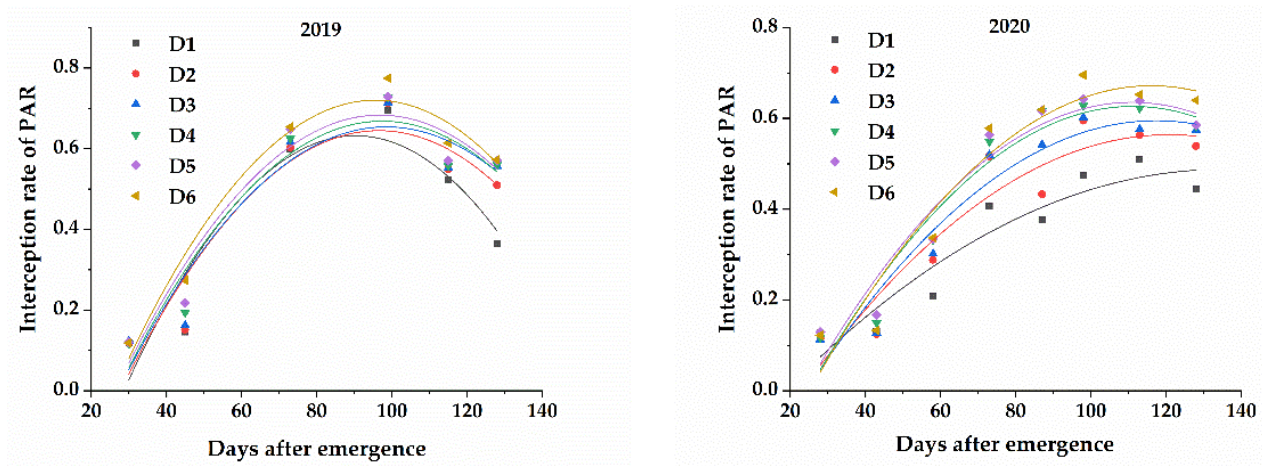

Figure 3. Interception rate of PAR at different planting densities in 2019 and 2020.

The changing trends of PAR per plant and the population PAR showed a quadratic curve with an opening downward. In the early stage of cotton growth, the light interception at different densities increased with increasing leaf area and peaked at approximately 100 DAE in both years. The maximum light interception per plant was 0.79 in 2019 and 0.73 in 2020, and the maximum light interception of the population was 0.77 in 2019 and 0.70 in 2020. In the later stage of cotton growth, the PAR of cotton decreased. The difference in light interception based on density was more obvious in 2020 than that in 2019. Comparing 
the PAR changes of cotton under the six different density treatments, the general trends of individual plants and the population in the two years were as follows: D6 > D5 > D4 > D3 $>$ D2 > D1.

\subsubsection{Leaf Area}

The results of the two-year sampling showed that the leaf area per plant and LAI showed a downward-opening parabola with the growth process (Supplementary Materials Figures S3 and S4).

For the change in leaf area per plant in two years, the D1 treatment showed middle values from emergence to $87 \mathrm{DAE}$, maximum values at $100 \mathrm{DAE}$, and then decreased. The leaf area per plant under D1 was as high as $8775 \mathrm{~cm}^{2}$ in 2019 and $6779 \mathrm{~cm}^{2}$ in 2020. The standard maximum error of the leaf area per plant among different density treatments was $89.80 \mathrm{~cm}^{2}$ in 2019 and $142.62 \mathrm{~cm}^{2}$ in 2020 .

For the change in the LAI in two years, there are significantly large differences in LAI among different densities in the peak growth period of cotton. The maximum standard error of LAI among different density treatments was 0.10 in 2019 and 0.09 in 2020. The maximum LAI under the high-density planting was 4.70 in 2019 and 3.28 in 2020. The maximum LAI under the low-density planting was 1.98 in 2019 and 1.29 in 2020. The LAI increased with increasing density, and the order of the LAI under the different densities was D6 > D5 > D4 > D3 > D2 > D1.

\subsubsection{Plant Height}

The two-year plant height showed an upward trend over the whole growth period and the following order: D6 > D5 > D4 > D3 > D2 > D1 (Supplementary Materials Figure S5).

The D6 treatment plants reached a maximum of $117.50 \mathrm{~cm}$ at 115 DAE in 2019 and $106.50 \mathrm{~cm}$ at 98 DAE in 2020, and the D1 density plants reached a maximum of $107.83 \mathrm{~cm}$ at 115 DAE in 2019 and $101.67 \mathrm{~cm}$ at 98 DAE in 2020. The maximum standard error of the plant height among different density treatments was $0.81 \mathrm{~cm}$ in 2019 and $0.45 \mathrm{~cm}$ in 2020 .

\subsubsection{Biomass}

Figures 4 and 5 reflect the changing trends in cotton biomass per plant and for the population under different planting densities from 2019 to 2020, which agree with the logistic growth model.
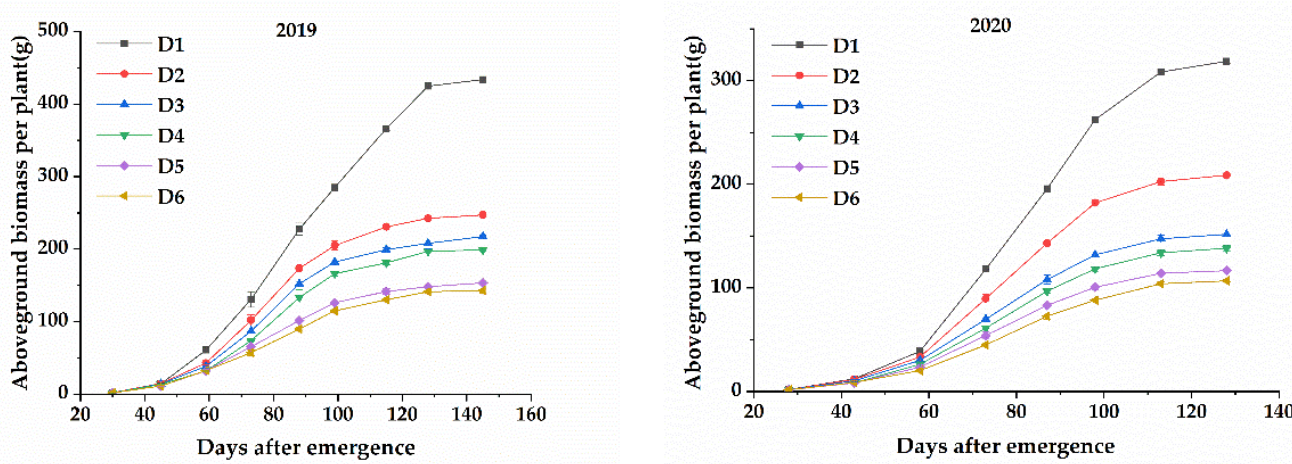

Figure 4. The aboveground biomass of a single cotton plant grown at different planting densities in 2019 and 2020.

Figure 4 shows that the biomass per plant of cotton under different densities showed an upward trend with the advancement of the growth process, the difference among densities was significant, and the D1 treatment had significantly higher biomass than the other density treatments. The maximum standard error of biomass per plant among different density treatments was $10.58 \mathrm{~g}$ in 2019 and $4.32 \mathrm{~g}$ in 2020. 
The biomass per plant under D1 reached $433.95 \mathrm{~g}$ at 145 DAE in 2019, $318.63 \mathrm{~g}$ at 128 DAE in 2020, and the biomass per plant under D6 reached $142.87 \mathrm{~g}$ at 145 DAE in 2019, and $106.78 \mathrm{~g}$ at $128 \mathrm{DAE}$ in 2020.
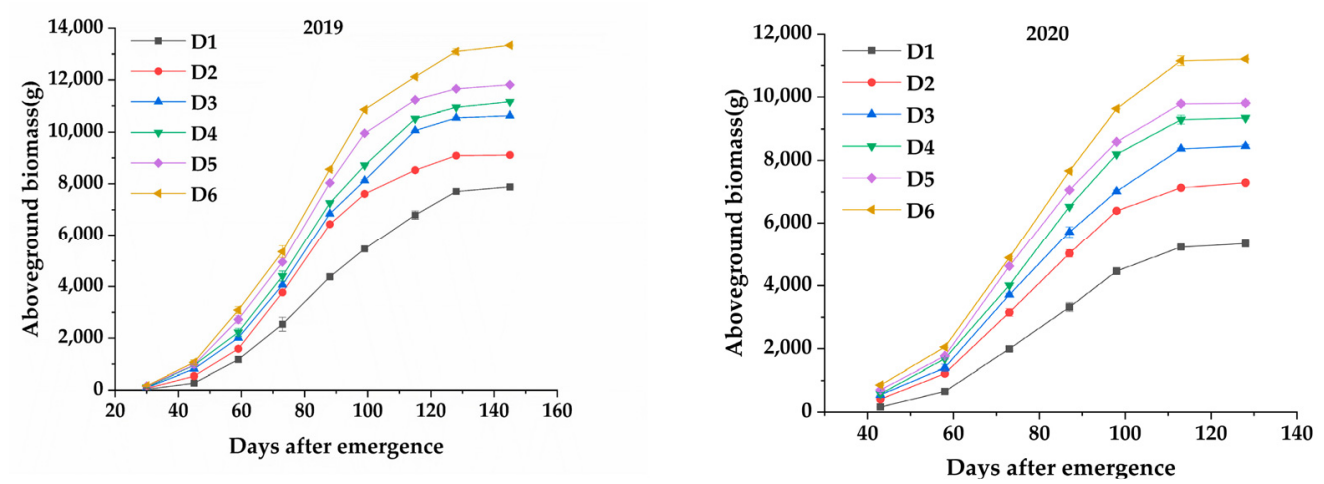

Figure 5. The aboveground biomass of cotton grown at different planting densities in 2019 and 2020.

With the advancement of the growth process, the population biomass of cotton under different densities showed an upward trend (Figure 5), and there were significant differences among different densities with the following order: D6 > D5 > D4 > D3 > D2 $>$ D1. The maximum standard error of the population biomass among different density treatments was $268.58 \mathrm{~g}$ in 2019 and $168.94 \mathrm{~g}$ in 2020. The highest biomass under D6 was $13,340.55 \mathrm{~g}$ at $145 \mathrm{DAE}$ in 2019 and 11,209.47 $\mathrm{g}$ at $128 \mathrm{DAE}$ in 2020. The highest biomass under D1 was $7884.86 \mathrm{~g}$ at 145 DAE in 2019 and $5340.10 \mathrm{~g}$ in 2020.

The dry matter accumulation under the different densities conformed to the logistic curve in two years. The fitting equation (Supplementary Materials Table S3) was based on Formula (4) and derived from Formula (4). The average growth rate and maximum growth rate under the different densities was calculated, as shown in Table 3. The start time, end time, and occurrence time of the fastest growth period are shown in Supplementary Materials Table S2.

Table 3. Characteristic values of biomass accumulation in the cotton growing season in 2019 and 2020.

\begin{tabular}{|c|c|c|}
\hline Treatment & $V_{A}\left(\mathrm{~kg} \cdot \mathrm{ha}^{-1} \cdot \mathrm{d}^{-1}\right)$ & $V_{M}\left(\mathrm{~kg} \cdot \mathrm{ha}^{-1} \cdot \mathrm{d}^{-1}\right)$ \\
\hline \multicolumn{3}{|c|}{ Year 2019} \\
\hline D1 & 114.2 & 130.2 \\
\hline D2 & 161.8 & 184.5 \\
\hline D3 & 163.0 & 186.0 \\
\hline D4 & 170.0 & 193.6 \\
\hline D5 & 189.1 & 215.6 \\
\hline D6 & 197.9 & 225.9 \\
\hline Average & 166.0 & 189.3 \\
\hline \multicolumn{3}{|c|}{ Year 2020} \\
\hline D1 & 101.1 & 115.2 \\
\hline D2 & 135.7 & 155.0 \\
\hline D3 & 146.8 & 167.6 \\
\hline D4 & 171.0 & 196.6 \\
\hline D5 & 180.2 & 205.8 \\
\hline D6 & 195.8 & 223.3 \\
\hline Average & 155.1 & 177.2 \\
\hline
\end{tabular}

Note: $\mathrm{V}_{\mathrm{A}}$ represents the average and $\mathrm{V}_{\mathrm{M}}$ represents the maximum rate of biomass accumulation. 
The average and maximum rate of biomass accumulation increased with increasing density in two years (Table 3 ). The average rate of biomass accumulation was $166.0 \mathrm{~kg} \cdot \mathrm{ha}^{-1} \cdot \mathrm{d}^{-1}$ in 2019 and $155.1 \mathrm{~kg} \cdot \mathrm{ha}^{-1} \cdot \mathrm{d}^{-1}$ in 2020 . The maximum rate of biomass accumulation was $189.3 \mathrm{~kg} \cdot \mathrm{ha}^{-1} \cdot \mathrm{d}^{-1}$ in 2019 and $177.2 \mathrm{~kg} \cdot \mathrm{ha}^{-1} \cdot \mathrm{d}^{-1}$ in 2020 . The Supplementary Materials Table 2 shows that the maximum dry matter accumulation under D6 was 13,469.5 $\mathrm{kg} \cdot \mathrm{ha}^{-1}$ in 2019 and $11,629.9 \mathrm{~kg} \cdot \mathrm{ha}^{-1}$ in 2020.

\subsubsection{Yield}

Table 4 shows that except for lint percentage, planting density had a significant effect on seed cotton yield, lint yield, boll number, and boll weight during the two-year period. The D5 treatment resulted in a high seed cotton yield, high lint yield, and high boll number per square meter in two years, followed by the D6 treatment. The other densities showed decreasing values with decreasing density, while the boll weight decreased with increasing density. The highest seed cotton yields were 4267.0 and $3689.3 \mathrm{~kg} \cdot \mathrm{ha}^{-1}$ in two years, which were 3.1, 4.4, 5.9, 10.4, and 26.1\% higher than those of D6, D4, D3, D2, and D1 in 2019, and $6.7,10.7,14.7,25.5$, and 39.5\% higher than those of D6, D4, D3, D2, and D1 in 2020, respectively. The highest lint yields were 1673.5 and $1375.4 \mathrm{~kg} \cdot \mathrm{ha}^{-1}$ in two years, which were 3.2, 4.3, 5.6, 9.7, and 24.7\% higher than those of D6, D4, D3, D2, and D1 in 2019, and $6.8,10.6,13.5,21.5$, and 34.4\% higher than those of D6, D4, D3, D2, and D1 in 2020, respectively. The highest number of bolls per square meter was 68.4 and 60.7 in two years, which was 2.4, 5.1, 7.7, 15.2, and 30.8\% higher than that of D6, D4, D3, D2, and D1 in 2019 and 4.5, 10.6, 15.2, 28.9, and 45.2\% higher than that of D6, D4, D3, D2, and D1 in 2020, respectively. In two years, the boll weight and lint percentage under D1 were the highest, and the rest decreased with increasing density.

Table 4. Cotton yield and yield components during the cotton growing season in 2019 and 2020.

\begin{tabular}{|c|c|c|c|c|c|}
\hline Treatment & Boll Number $\left(\mathrm{m}^{2}\right)$ & Boll Weight (g) & $\begin{array}{l}\text { Seed Cotton Yield } \\
\left(\mathrm{kg} \cdot \mathrm{ha}^{-1}\right)\end{array}$ & $\begin{array}{l}\text { Lint Yield } \\
\left(\mathrm{kg} \cdot \mathrm{ha}^{-1}\right)\end{array}$ & $\begin{array}{c}\text { Lint Percentage } \\
(\%)\end{array}$ \\
\hline \multicolumn{6}{|c|}{ Year 2019} \\
\hline D1 & $52.3^{c}$ & $6.5^{\mathrm{a}}$ & $3383.1^{b}$ & $1342.1^{b}$ & $39.6^{a}$ \\
\hline D2 & $59.4^{b}$ & $6.5^{\mathrm{a}}$ & $3866.6^{a}$ & $1525.0^{\mathrm{a}}$ & $39.4^{\mathrm{a}}$ \\
\hline D3 & $63.5^{a b}$ & $6.4^{\mathrm{ab}}$ & $4030.8^{a}$ & $1584.7^{\mathrm{a}}$ & $39.3^{a}$ \\
\hline $\mathrm{D} 4$ & $65.1^{a b}$ & $6.3^{b}$ & $4088.0^{a}$ & $1603.9^{a}$ & $39.2^{\mathrm{a}}$ \\
\hline D5 & $68.4^{\mathrm{a}}$ & $6.2^{b}$ & $4267.0^{a}$ & $1673.5^{\mathrm{a}}$ & $39.2^{\mathrm{a}}$ \\
\hline D6 & $66.8^{a}$ & $6.2^{b}$ & $4139.0^{\mathrm{a}}$ & $1620.9^{a}$ & $39.2^{a}$ \\
\hline \multicolumn{6}{|c|}{ Year 2020} \\
\hline D1 & $41.8^{\mathrm{d}}$ & $6.3^{a}$ & $2645.1^{d}$ & $1023.7^{d}$ & $38.7^{\mathrm{a}}$ \\
\hline D2 & $47.1^{\mathrm{cd}}$ & $6.2^{\mathrm{ab}}$ & $2939.7^{c d}$ & $1132.1^{\mathrm{cd}}$ & $38.6^{a}$ \\
\hline D3 & $52.7^{b c}$ & $6.1^{\mathrm{ab}}$ & $3215.9^{b c}$ & $1212.2^{b c}$ & $37.7^{\mathrm{a}}$ \\
\hline $\mathrm{D} 4$ & $54.9^{a b}$ & $6.1^{\mathrm{ab}}$ & $3332.6^{a b c}$ & $1244.1^{\mathrm{abc}}$ & $37.3^{a}$ \\
\hline D5 & $60.7^{a}$ & $6.1^{\mathrm{ab}}$ & $3689.3^{a}$ & $1375.4^{\mathrm{a}}$ & $38.3^{a}$ \\
\hline D6 & $58.1^{\mathrm{ab}}$ & $6.0^{b}$ & $3458.7^{a b}$ & $1288.1^{\mathrm{ab}}$ & $37.2^{\mathrm{a}}$ \\
\hline \multicolumn{6}{|c|}{ Variance Analysis } \\
\hline Year(Y) & $* *$ & $* *$ & $* *$ & $* *$ & $* *$ \\
\hline Treatment(T) & $* *$ & $* *$ & $* *$ & $* *$ & * \\
\hline $\mathrm{Y}^{*} \mathrm{~T}$ & NS & NS & NS & NS & NS \\
\hline
\end{tabular}

Note: According to Duncan's multiple range test, different lowercase letters in the superscript of the number indicate significant differences $(p<0.05) .{ }^{*}$ and ${ }^{* *}$ indicate significant differences at the 0.05 and 0.01 levels, respectively. NS means the difference is not significant $(p>0.05)$. 


\subsection{The Relationships and Fitted Models}

After fitting, it was found that there was a logarithmic relationship between iPAR per plant and leaf area per plant in two years (Supplementary Materials Figure S6), with an $R^{2}$ value of 0.86 . There was a significant linear relationship between cumulative iPAR per plant and aboveground biomass per plant (Figure 6), with an $\mathrm{R}^{2}$ value of 0.64 .

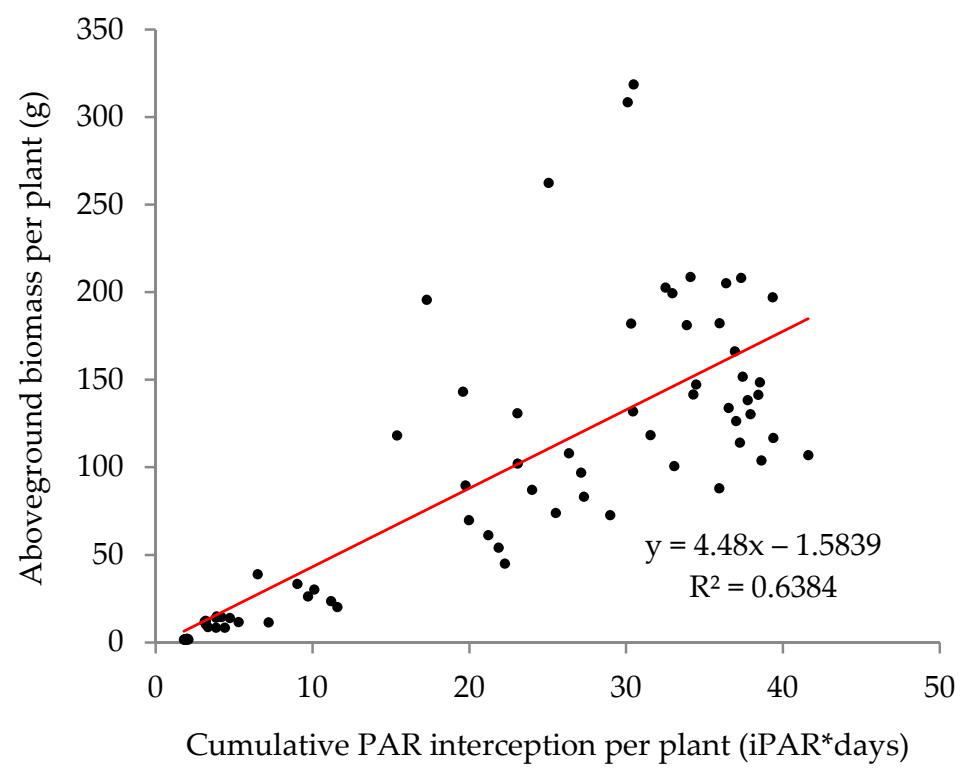

Figure 6. Relationships and fitted models between iPAR per plant and aboveground biomass per plant in 2019 and 2020. iPAR*days means iPAR's integral of the number of growth days.

There was a logarithmic relationship between the population cumulative iPAR and LAI (Supplementary Materials Figure S7), and the $\mathrm{R}^{2}$ value was 0.91 . There was a significant linear relationship between the population cumulative iPAR and plant height (Supplementary Materials Figure S7), with an $\mathrm{R}^{2}$ value of 0.88 . There was a significant linear relationship between the population cumulative iPAR and the population biomass (Figure 7), with an $R^{2}$ value of 0.93 . The population cumulative iPAR and boll number showed a significant linear relationship in two years (Figure 7), with $R^{2}$ values of 0.92 and 0.76 , respectively. There was a significant linear relationship between the population cumulative iPAR and boll weight in two years (Figure 7), with $R^{2}$ values of 0.53 and 0.90 , respectively.
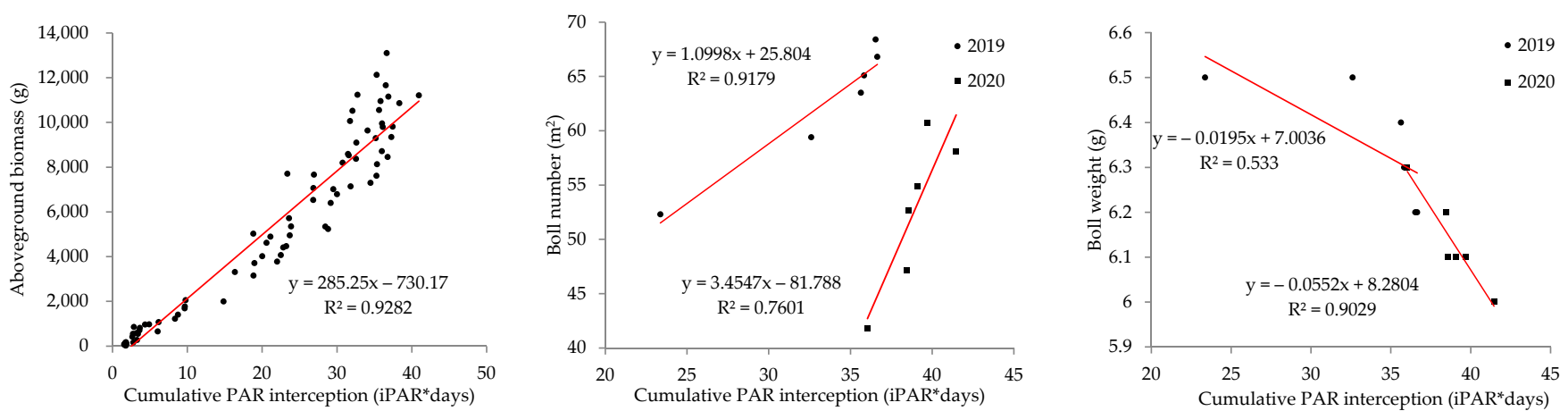

Figure 7. Relationships and fitted models between the population iPAR and aboveground biomass, boll number, and boll weight in 2019 and 2020. iPAR*days means iPAR's integral of the number of growth days. 
3.3. Relationships between the Competition for Light under Different Densities and the Distribution of Yield

3.3.1. Spatial Distribution Map of Boll Retention and Shedding Rate

Taking the number of large bolls, small bolls, boll opening, and shedding in the last plant diagram, Surfer was used to map the spatial distribution of the boll retention and shedding rate. The results are shown in Figures 8 and 9.

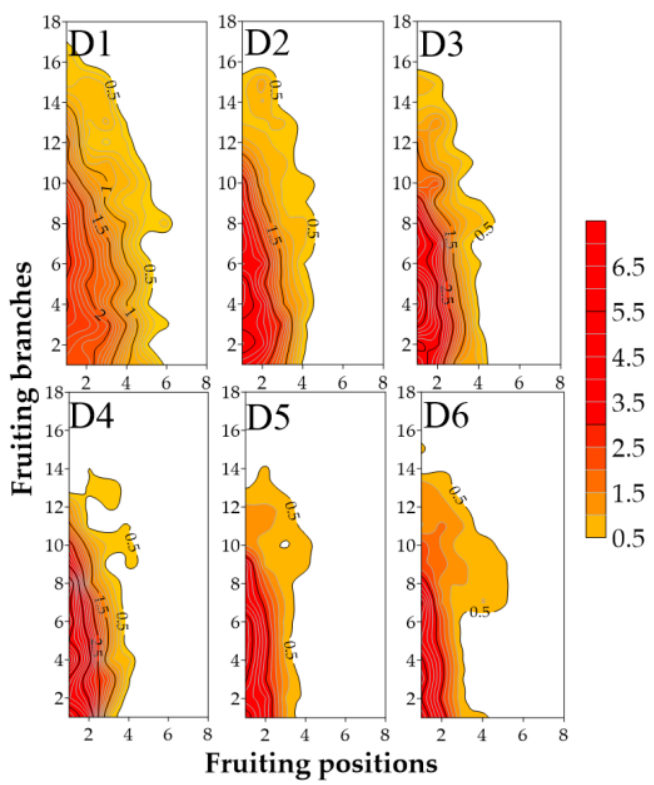

Figure 8. Spatial distribution of the boll retention rate of cotton yield at different densities in 2019 and 2020.

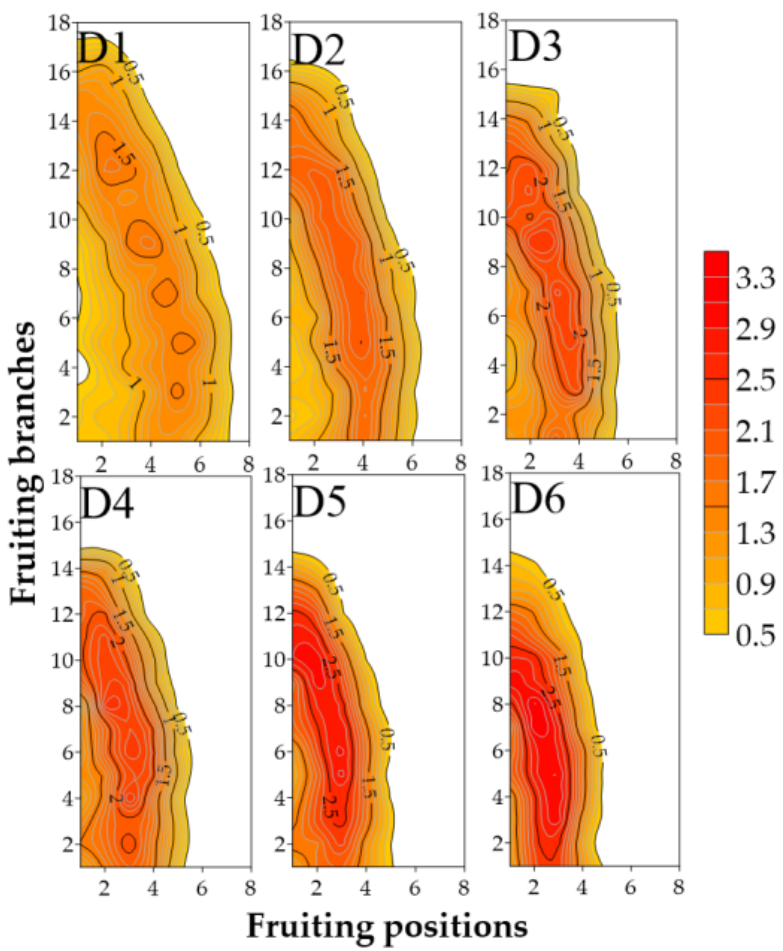

Figure 9. Spatial distribution of the boll shedding rate of per plant at different densities in 2019 and 2020 . 
From the horizontal fruit nodes, the boll retention rate under the different densities decreased from the inside to the outside in two years (Figure 8). For the longitudinal fruiting branches, the boll retention rate under different densities decreased from the bottom to the top in two years. The highest fruiting branch position was D1 > D3 $>$ D2 > D6 > D5 > D4 in two years. The distribution of cotton bolls was mainly concentrated in the inner fruit nodes, mostly in fruit nodes 1-4. Additionally, in the horizontal position, with increasing density, the cotton boll distribution was more concentrated in the interior.

The shedding rate under the different densities decreased from the inside to the outside in terms of the horizontal fruit nodes, and from the bottom to the top in terms of the longitudinal fruiting branches in two years (Figure 9). The highest fruiting branch position was D1 > D2 > D3 > D4 > D5 > D6. The shedding of bolls was mainly concentrated in the outer fruit nodes, and in the horizontal position, while with the increase in the cotton population density, the shedding appeared closer to the main stem.

\subsubsection{Comparison of the Boll Retention and Shedding Rate in Different Sections under} Different Densities

According to the different positions of bolls on cotton plants, cotton bolls were longitudinally divided into three sections: lower (1-5 fruiting branches), middle (6-10 fruiting branches), and upper (more than 10 fruiting branches). Horizontally, cotton bolls were divided into two sections: inner (one to two fruit nodes) and outer (outside two fruit nodes). The boll retention rate of each section is shown in Table 5, and the shedding rate of each section is shown in Table 6.

Table 5. The boll retention rate of different sections with different densities in 2019 and 2020.

\begin{tabular}{|c|c|c|c|c|c|}
\hline Treatment & Lower & Middle & Upper & Inner & Outer \\
\hline \multicolumn{6}{|c|}{ Year 2019} \\
\hline D1 & $0.421^{\mathrm{a}}$ & $0.355^{a}$ & $0.224^{a}$ & $0.549^{b}$ & $0.451^{a}$ \\
\hline D2 & $0.449^{a}$ & $0.363^{a}$ & $0.188^{a}$ & $0.695^{\mathrm{a}}$ & $0.305^{b}$ \\
\hline D3 & $0461^{a}$ & $0.357^{a}$ & $0.182^{a}$ & $0.742^{a}$ & $0.258^{b}$ \\
\hline D4 & $0.501^{\mathrm{a}}$ & $0.383^{a}$ & $0.116^{a}$ & $0.780^{a}$ & $0.220^{b}$ \\
\hline D5 & $0.509^{a}$ & $0.365^{a}$ & $0.126^{a}$ & $0.781^{a}$ & $0.219^{b}$ \\
\hline D6 & $0.461^{a}$ & $0.370^{a}$ & $0.169^{a}$ & $0.800^{\mathrm{a}}$ & $0.200^{b}$ \\
\hline \multicolumn{6}{|c|}{ Year 2020} \\
\hline D1 & $0.447^{a}$ & $0.385^{a}$ & $0.167^{a}$ & $0.578^{c}$ & $0.422^{a}$ \\
\hline D2 & $0.498^{a}$ & $0.372^{a}$ & $0.129^{a b}$ & $0.713^{b c}$ & $0.287^{a b}$ \\
\hline D3 & $0.567^{a}$ & $0.354^{a}$ & $0.079 \mathrm{ab}$ & $0.801^{a b}$ & $0.199 \mathrm{bc}$ \\
\hline D4 & $0.527^{a}$ & $0.399^{a}$ & $0.073^{a b}$ & $0.804^{a b}$ & $0.196^{b c}$ \\
\hline D5 & $0.572^{a}$ & $0.381^{a}$ & $0.046^{b}$ & $0.915^{a}$ & $0.085^{c}$ \\
\hline D6 & $0.564^{a}$ & $0.355^{a}$ & $0.081^{\mathrm{ab}}$ & $0.855^{a b}$ & $0.145^{b c}$ \\
\hline
\end{tabular}

Note: According to Duncan's multiple range test, different lowercase letters in the superscript of the number indicate significant differences $(p<0.05)$.

The boll retention rate of lower fruiting branches and inner fruit nodes of cotton plants were higher (Table 5). The lower fruit branch of cotton plants under D5 reached 0.509 in 2019 and 0.572 in 2020, and the inner fruit node of D6 reached 0.800 and 0.915, respectively. Different densities had significant effects on the boll distribution of cotton. Longitudinally, there was no significant difference among the lower, middle, and upper fruiting branches in 2019. There was no significant difference in the boll retention rate of lower and middle fruit branches among different densities in 2020, while the retention rate of the upper section under D1 was the highest, and that under D5 was the lowest. 
Horizontally, the surrounding bolls increased with increasing density in 2019 , and the peripheral bolls decreased with increasing density. In 2020, the circumference of D5 was the highest, and those of the rest increased with increasing density, while the periphery of D5 was the lowest, and those of the rest decreased with increasing density.

Table 6. The shedding rate of different sections with different densities in 2019 and 2020.

\begin{tabular}{|c|c|c|c|c|c|}
\hline Treatment & Lower & Middle & Upper & Inner & Outer \\
\hline \multicolumn{6}{|c|}{ Year 2019} \\
\hline D1 & $0.349^{\mathrm{a}}$ & $0.344^{c}$ & $0.307^{\mathrm{a}}$ & $0.378^{a}$ & $0.622^{\mathrm{a}}$ \\
\hline D2 & $0.357^{\mathrm{a}}$ & $0.381^{b c}$ & $0.262^{a b}$ & $0.389^{\mathrm{a}}$ & $0.611^{\mathrm{a}}$ \\
\hline D3 & $0.356^{\mathrm{a}}$ & $0.411^{\mathrm{ab}}$ & $0.234^{\mathrm{ab}}$ & $0.527^{\mathrm{a}}$ & $0.473^{a}$ \\
\hline D4 & $0.411^{a}$ & $0.411^{\mathrm{ab}}$ & $0.179^{a b}$ & $0.562^{\mathrm{a}}$ & $0.438^{a}$ \\
\hline D5 & $0.380^{a}$ & $0.454^{\mathrm{a}}$ & $0.166^{a b}$ & $0.592^{\mathrm{a}}$ & $0.408^{a}$ \\
\hline D6 & $0.430^{\mathrm{a}}$ & $0.443^{\mathrm{a}}$ & $0.126^{b}$ & $0.585^{\mathrm{a}}$ & $0.416^{\mathrm{a}}$ \\
\hline \multicolumn{6}{|c|}{ Year 2020} \\
\hline D1 & $0.333^{c}$ & $0.332^{c}$ & $0.335^{a}$ & $0.275^{\mathrm{e}}$ & $0.725^{a}$ \\
\hline D2 & $0.338^{c}$ & $0.356^{c}$ & $0.306^{a}$ & 0.364 de & $0.636^{\mathrm{ab}}$ \\
\hline D3 & $0.368^{b c}$ & $0.391^{b}$ & $0.241^{b}$ & $0.408^{c d}$ & $0.592^{b c}$ \\
\hline D4 & $0.397^{a b}$ & $0.395^{b}$ & $0.208^{b}$ & $0.477^{b c}$ & $0.523^{\mathrm{cd}}$ \\
\hline D5 & $0.392^{\mathrm{ab}}$ & $0.404^{b}$ & $0.203^{b}$ & $0.508^{a b}$ & 0.492 de \\
\hline D6 & $0.415^{\mathrm{a}}$ & $0.439^{\mathrm{a}}$ & $0.146^{c}$ & $0.582^{\mathrm{a}}$ & $0.418^{\mathrm{e}}$ \\
\hline
\end{tabular}

Note: According to Duncan's multiple range test, different lowercase letters in the superscript of the number indicate significant differences $(p<0.05)$.

The shedding rate of the middle fruiting branches and peripheral fruit nodes of cotton plants was relatively high (Table 6). The middle fruiting branches of D5 reached 0.454 in 2019, those of D6 reached 0.439 in 2020, and the peripheral fruit nodes of D1 reached 0.622 in 2019 and 0.725 in 2020. Different densities had a significant effect on the shedding rate of cotton. Longitudinally, there was no significant difference in the shedding rate of the lower fruiting branch in 2019. The middle fruiting branch of D5 had the highest rate, and the shedding rate of the other density increased with the increase of the density, while that of the upper fruiting branch decreased with increasing density. In 2020, the shedding rate of lower fruiting branches was D6 $>$ D4 $>$ D5 $>$ D3 $>$ D2 $>$ D1, the middle fruiting branches showed an increased rate with increasing density, and the upper section showed a decreasing rate with increasing density. Horizontally, there was no significant difference in the shedding rate between the inner circumference and the periphery in 2019. In 2020, the shedding rate of peripheral fruit nodes increased with increasing density, while that of the periphery decreased with increasing density.

3.3.3. Relationships between iPAR and the Boll Retention Rate in the Lower, Middle, Upper, Inner, and Outer Sections of Cotton Plants

The correlation between the boll retention rate of different sections and the corresponding light interception rate was established (Figure 10).

The results of Figure 10 show that there was a negative linear correlation between the cumulative light interception rate of each section and the boll retention rate of the corresponding region, which means the higher the cumulative light interception rate was, the smaller the boll retention rate. In the vertical direction, the correlation between the lower light interception and the boll retention rate was the highest (0.91), followed by the middle (0.17) and the upper (0.12). In the horizontal direction, the correlation 
values between inner and outer light interception and the boll retention rate were 0.52 and 0.76 , respectively.

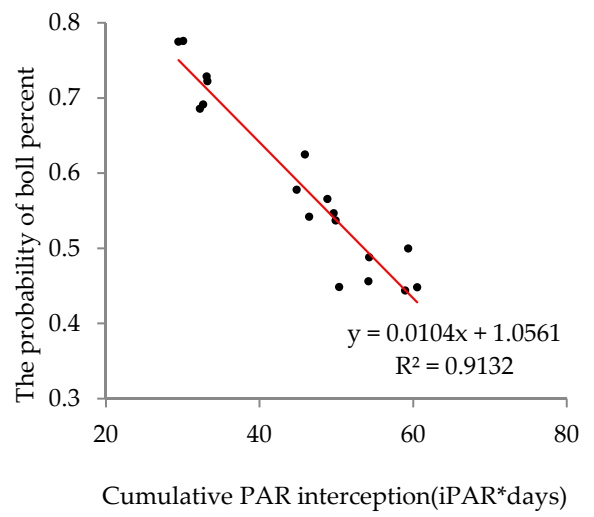

(a)

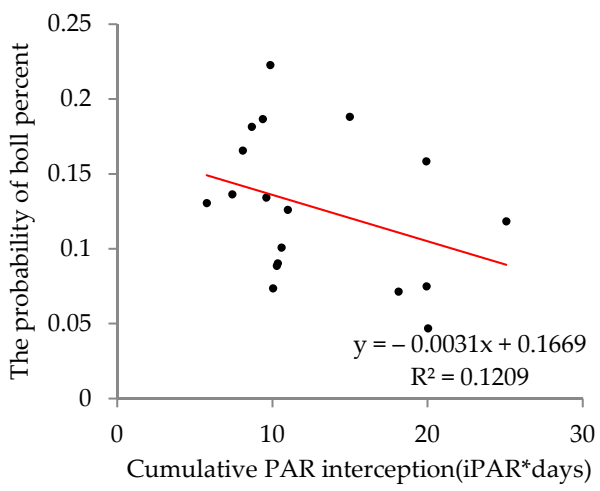

(c)

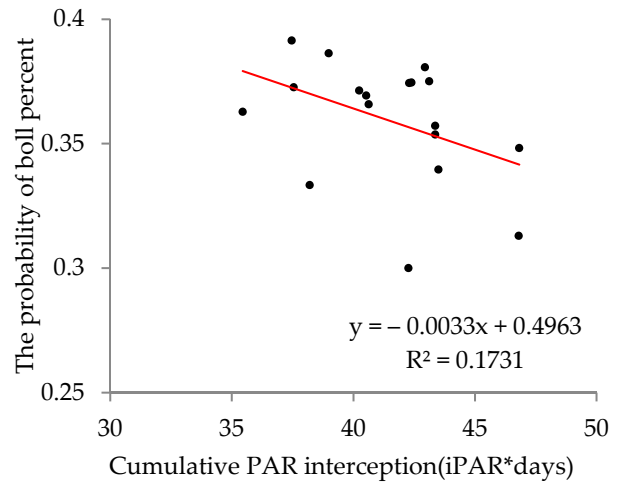

(b)

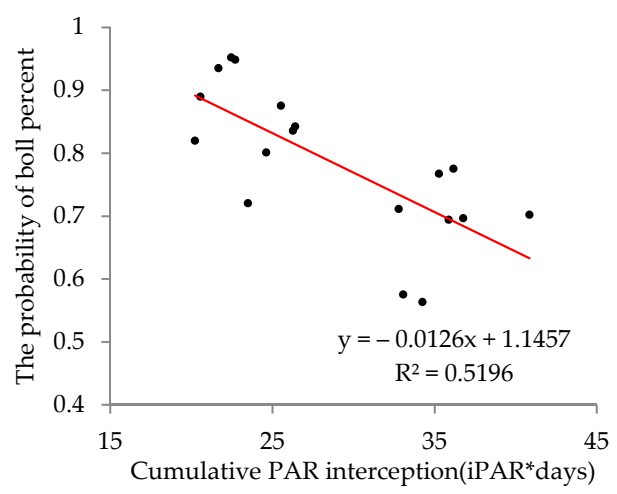

(d)

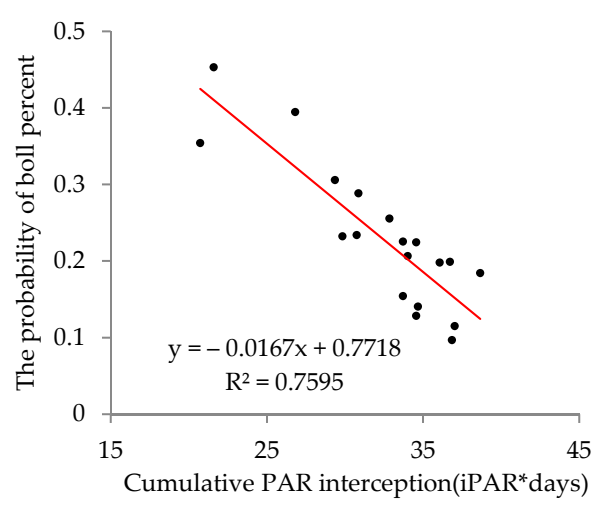

(e)

Figure 10. Relationships between cumulative light interception and the boll retention rate in the corresponding section. (a) Lower; (b) Middle; (c) Upper; (d) Inner; (e) Outer. iPAR*days means iPAR's integral of the number of growth days.

3.3.4. Relationships between iPAR and the Boll Shedding Rate of Lower, Middle, and Upper Sections of Cotton Plants

As seen from Figure 11, the cumulative light interception in different sections and the boll shedding rate of the corresponding region showed a quadratic upward curve, which means, with the increase in cumulative light interception, the shedding rate decreased first and then increased. In the vertical direction, the correlation value between the cumulative light interception in the lower section and the boll shedding rate in the corresponding 
region was 0.96 , that in the middle was 0.92 , and that in the lower section was 0.24 , and the order was lower $>$ middle $>$ upper section. In the horizontal direction, the shedding rate was related to light interception of the inner perimeter, with an $\mathrm{R}^{2}$ value of 0.44 , and that of the outer periphery was 0.50 , and the order was outer $>$ inner periphery.

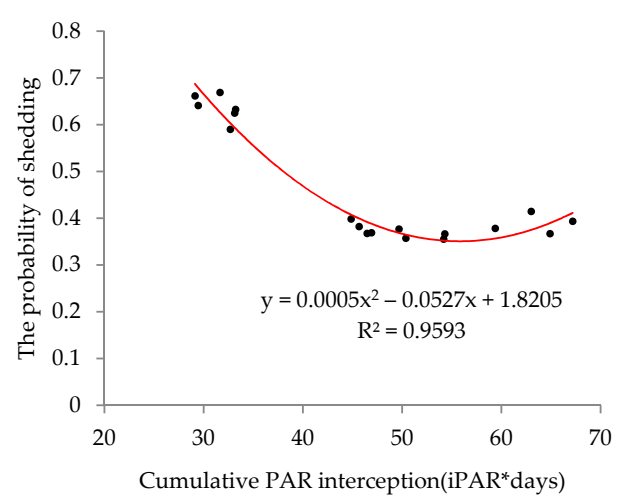

(a)

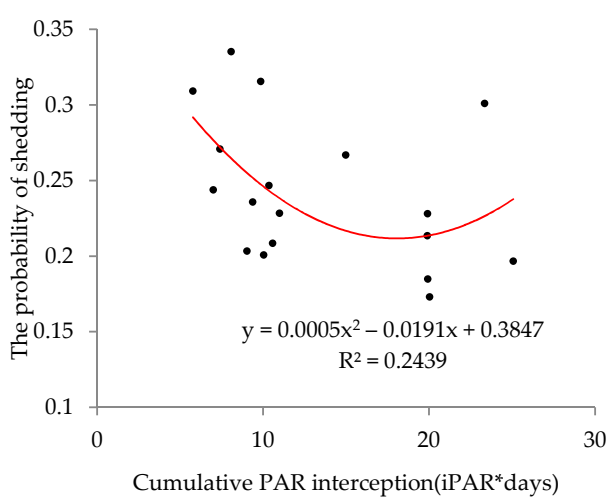

(c)

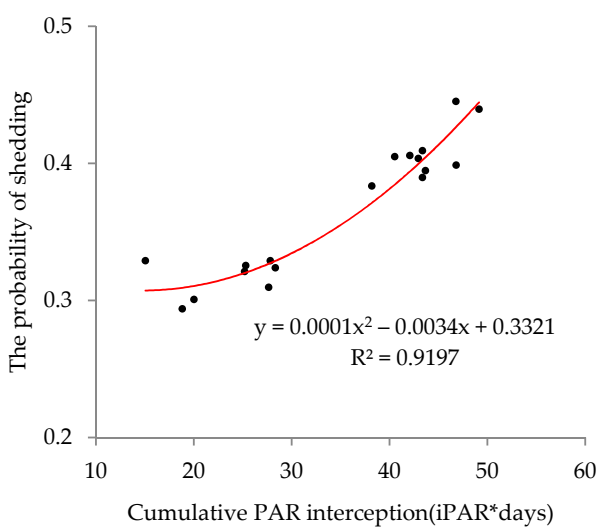

(b)

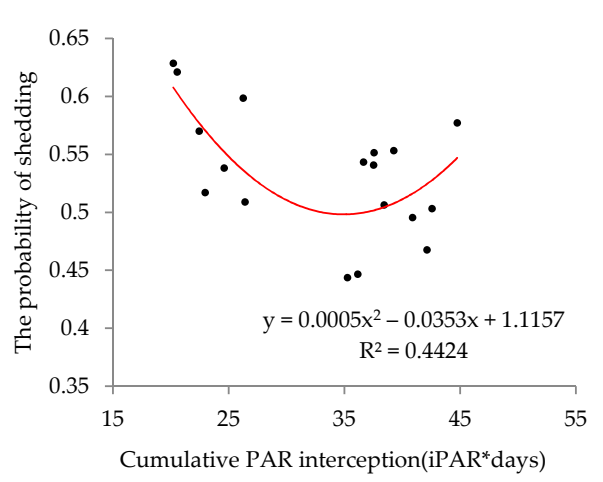

(d)

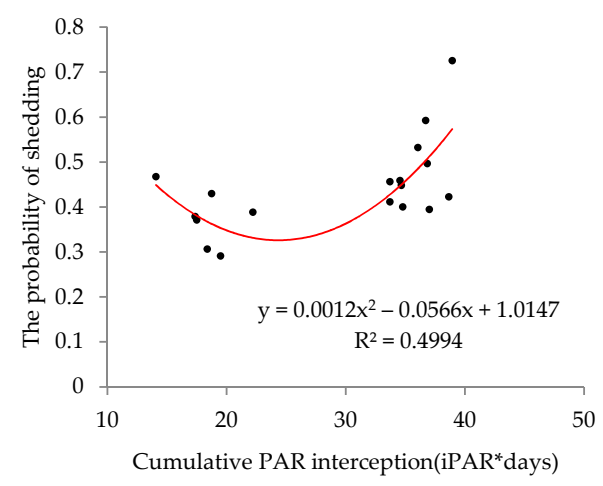

(e)

Figure 11. Relationships between cumulative light interception and the boll shedding rate in the corresponding section. (a) Lower; (b) Middle; (c) Upper; (d) Inner; (e) Outer. iPAR*days means iPAR's integral of the number of growth days.

\section{Discussion}

Due to the different spaces occupied by individual plants, cotton plants with different densities compete for light, heat, water, and fertilizer, and different planting densities result in different intensities of competition and light energy utilization efficiencies [26]. Zhang pointed out that the light interception of cotton increased with increasing density [27]. This 
is consistent with the change of the light interception in this study. The variation in the leaf area index was similar to that of the population photosynthetic rate, as the LAI of high density reached a peak at the full boll stage [28], and the plant height increased first and then remained steady and reached a maximum at the flowering and boll development stage [29]. The result was consistent with the change law of the leaf area index and plant height in this paper.

The source of cotton growth is carbohydrates produced by photosynthesis, and different populations have different light distributions and solar radiation energy utilization $[23,24]$. There are differences in the characteristic values of dry matter accumulation among different planting densities [25]. Because the individual space per plant was sufficient for development, the competition was low, and the light interception was high. The dry matter accumulation per plant under the low-density treatment was much higher than that under the high-density treatment, the dry matter accumulation under the low-density treatment was lower than that under the high-density treatment, and the dry matter accumulation of single plants and the population treated with medium density tended to be reasonable. This was consistent with the research results of Han and Weiner [30,31]. In two years, the seed cotton yield, lint yield, and boll number per square meter of the D5 treatment were the highest, followed by those of D6, D4, D3, D2, and D1, and the boll weight decreased with increasing density. This conclusion was consistent with the results of Mao, who showed that the high yield of D5 may have been due to the high number of bolls per unit area [32].

The LAI is an important index to reflect the light interception ability of crops and to construct a reasonable canopy structure [33]. Robinson found that the leaf elongation rate and the number of leaf cells determine the leaf size, thus affecting iPAR [34]. Houx found that biomass accumulation was closely related to iPAR [35]. Plants will produce shade avoidance responses when they perceive a shaded environment, which leads to an increase of the plant height [36]. In the higher density population, plants had a canopy architecture with low K-values and light penetrated deeper into the canopy [37]. There was a significant positive correlation between yield and iPAR among different rice varieties [38]. When the population density was high, the utilization efficiency of available resources was low [10]. The photosynthate transport efficiency under a wide row spacing was higher than that under a narrow row spacing, and the boll weight under a wide row spacing was higher than that under a narrow row spacing [17]. The results of this study showed a significant linear relationship between iPAR and LAI, plant height, biomass, boll number, and boll weight, which was consistent with previous studies.

The light interception of the crop canopy had a direct impact on crop production [39], and there were differences in the boll retention and shedding distribution among different densities. In this experiment, the high planting density resulted in a higher fruiting branch number and fruit node number than the low planting density because the planting density was negatively correlated with the number of fruiting branches per plant [40]. The distribution of cotton bolls was mainly concentrated in the lower fruiting branches and the inner fruit nodes, and the boll retention rate of D5 was higher, which was consistent with the boll retention distribution with the plant type cultivation method studied by Zhu [41]. The shedding of boll was mainly concentrated in the outer fruit nodes of the middle and lower fruiting branches, and the boll shedding rate increased with increasing density. Because the high-density canopy was relatively closed, especially in the middle and lower sections, the light transmission is less [42], and then the temperature decreases and the relative humidity increases [43], resulting in an increase in boll shedding. Li thought that the closer squares and bolls are to the main stem, the fewer fall off, and the greater bolls formed [44]. In contrast, the further the squares and bolls are away from the main stem, the greater number that fall off and the fewer bolls formed. Our conclusion was consistent with these findings.

The analysis of the dynamics of light energy utilization and yield distribution of cotton is helpful to understand the factors affecting the growth, development, and yield 
of cotton, and put forward the technical measures to achieve high quality and high yield according to the actual production problems [45]. The growth and development of reproductive organs is highly correlated with the photosynthates formed by light interception of adjacent leaves [46], which is consistent with the correlation between the boll retention rate and shedding rate in different sections and light interception in their corresponding sections. The correlation between the boll retention rate and shedding rate of the lower and peripheral areas and light interception was the highest, so improving the distribution of light in the middle and inner periphery can significantly increase cotton yield.

\section{Conclusions}

The results showed that different density planting patterns affected the light interception of the cotton canopy, and thus the yield and boll distribution. The D5 treatment $\left(87,000\right.$ plants $\cdot$ ha $\left.^{-1}\right)$ could make better use of light energy and obtained the highest yields in both years. The boll retention rate and shedding rate in the lower part of cotton plants are most closely related to light interception. The light distribution in the middle and inner part of cotton plants need to be improved. The results provide a significant basis for improving light interception by optimizing planting density and canopy structure to achieve higher cotton yield.

Supplementary Materials: The following are available online at https:/ /www.mdpi.com/article/ 10.3390/agronomy11112346/s1, Figure S1: Measurement point between the two lines of cotton; Figure S2: The spatial distribution of the interception of PAR in the different section; Figure S3: Leaf area per cotton plant growing at different planting densities in 2019 and 2020; Figure S4: Leaf area index of cotton plants growing at different planting densities in 2019 and 2020; Figure S5: Cotton plant height at different planting densities in 2019 and 2020; Figure S6: Relationships and fitted models between iPAR per plant and leaf area per plant in 2019 and 2020; Figure S7: Relationships and fitted models between the population iPAR and LAI, plant height in 2019 and 2020. Table S1: English abbreviation table; Table S2: Characteristic value of biomass accumulation in cotton growing season in 2019 and 2020; Table S3: Fitting equation of dry matter accumulation process in different density population from 2019 to 2020 .

Author Contributions: Y.L. (Yabing Li) and Y.H. designed the experiment. W.D., B.Y., S.X. and M.X. conducted the experiment. Y.L. (Yaping Lei), F.X., L.F., X.L. and G.W. helped and provided useful suggestions during the experiment. Q.W. processed and analyzed data and wrote the first draft. H.C. helped to write first draft. Y.L. (Yabing Li), Z.W. and L.F. revised and edited the manuscript. All authors have read and agreed to the published version of the manuscript.

Funding: We are thankful for the financial support by National Natural Science Foundation of China (32001480). The funder had no role in design, data collection and decision to publish or preparation of manuscript.

Institutional Review Board Statement: Not applicable.

Informed Consent Statement: Not applicable.

Data Availability Statement: Not applicable.

Acknowledgments: We highly acknowledge the help of technicians of the research station from the institute of cotton research Chinese Academy of Agricultural Sciences.

Conflicts of Interest: The authors declare no conflict of interests.

\section{References}

1. Craine, J.M.; Dybzinski, R. Mechanisms of plant competition for nutrients, water and light. Funct. Ecol. 2013, 27, 833-840. [CrossRef]

2. Craine, J. Resource Strategies of Wild Plants; Princeton University Press: Princeton, NJ, USA, 2009

3. Wu, K.; Mei, H.; Chen, Z.; Wang, N.; Wu, P. Plant light competitive relationship and its influence factors: Research advances. Chin. Agric. Sci. Bull. 2018, 84, 57-62.

4. Li, X.; Wang, J.; Zheng, J.; Liang, Y.; Gong, Z.; Ai, X.; Zhang, Z.; Mai, M.; Guo, J. Explore to establish the cotton industry development pattern that the whole industry chain adds value in Xinjiang. Cotton Sci. 2020, 42, $20-25$. 
5. Li, P.; Lei, Y.; Li, Y.; Wei, X. Development status quo of China's cotton industry and its outlook. Agric. Outlook 2016, $12,38-45$.

6. Zhang, P.; Yu, M.; Tuo, H.; Wang, X.; Zhao, X.; Liu, N.; He, H.; Bian, J. Constructing the production technology system of regional brand special cotton to improve the quality and market competitiveness of cotton in Xinjiang. Xinjiang Agric. Sci. 2008, 45, 181-184.

7. Wang, P.; Kinnucan, H.W.; Duffy, P.A. The effects of rising labour costs on global supply chains: The case of China's cotton yarn industry. Appl. Econ. 2019, 51, 3608-3623. [CrossRef]

8. Zhai, X.; Zhang, W. The thinking and judgment of the present situation of China's cotton industry and its future development trend. Agric. Dev. Financ. 2014, 55-60.

9. Xie, T.; Su, P.; An, L.; Shan, L.; Zhou, Z.; Chai, Z. Physiological characteristics of high yield under cluster planting: Photosynthesis and canopy microclimate of cotton. Plant Prod. Sci. 2016, 19, 165-172. [CrossRef]

10. Huber, M.; Nieuwendijk, N.; Pantazopoulou, C.; Pierik, R. Light signalling shapes plant-plant interactions in dense canopies. Plant Cell Environ. 2021, 44, 1014-1029. [CrossRef]

11. Olsen, J.; Kristensen, L.; Weiner, J. Influence of sowing density and spatial pattern of spring wheat (Triticum aestivum) on the suppression of different weed species. Weed Biol. Manag. 2006, 6, 165-173. [CrossRef]

12. Hao, F. Niche of chimonanthus praecox in northwestern Hunan province. J. Jiangsu Univ. 2007, 28, 180-184.

13. Liu, X.; Wang, W.; Lin, X.; Gu, S.; Wang, D. The effects of intraspecific competition and light transmission within the canopy on wheat yield in a wide-precision planting pattern. J. Integr. Agric. 2020, 19, 1577-1585. [CrossRef]

14. Chu, C.J.; Weiner, J.; Maestre, F.T.; Wang, Y.S.; Morris, C.; Xiao, S.; Yuan, J.; Du, G.; Wang, G. Effects of positive interactions, size symmetry of competition and abiotic stress on self-thinning in simulated plant populations. Ann. Bot. 2010, 106, 647-652. [CrossRef] [PubMed]

15. Liu, T.; Li, C.; Fu, J.; Yan, C. Population quality of different Maize (Zea mays L.) genotypes intercropped. Acta Ecol. Sin. 2009, 29, 6302-6309.

16. Zhang, W.; Wang, Z.; Yu, S.; Li, S.; Fang, J.; Tong, W. Effects of planting density on canopy photosynthesis, canopy structure and yield formation of high-yield cotton in Xinjiang, China. Acta Phytoecol. 2004, 28, 164-171.

17. Yao, H.; Zhang, Y.; Yi, X.; Zuo, W.; Lei, Z.; Sui, L.; Zhang, W. Characters in light-response curves of canopy photosynthetic use efficiency of light and $\mathrm{N}$ in responses to plant density in field-grown cotton. Field Crop. Res. 2017, 203, 192-200. [CrossRef]

18. Gu, S.; Evers, J.B.; Zhang, L.; Mao, L.; Zhang, S.; Zhao, X.; Liu, S.; Werf, W.; Li, Z. Modelling the structural response of cotton plants to mepiquat chloride and population density. Ann. Bot. 2014, 114, 877-887. [CrossRef] [PubMed]

19. Ayaz, S.; Mckenzie, B.A.; Mcneil, D.L.; Hill, G.D. Light interception and utilization of four grain legumes sown at different plant populations and depths. J. Agric. Sci. 2004, 142, 297-308. [CrossRef]

20. Ping, X.; Zhou, G.; Sun, J. Advances in the study of photosynthate allocation and its controls. Chin. J. Plant Ecol. 2010, $34,100-111$.

21. Ringselle, B.; Prieto-Ruiz, I.; Andersson, L.; Aronsson, H.; Bergkvist, G. Elymus repens biomass allocation and acquisition as affected by light and nutrient supply and companion crop competition. Ann. Bot. 2017, 119, 477-485. [CrossRef] [PubMed]

22. Tang, Q. Studys on Canopy Photosynthesis Characteristic of Cotton with Different Leaf-Type; Shihezi University: Shihezi, China, 2009.

23. Zhi, X.; Han, Y.; Mao, S.; Wang, G.; Feng, L.; Yang, B.; Fan, Z.; Du, W.; Lu, J.; Li, Y. Light spatial distribution in the canopy and crop development in cotton. PLoS ONE 2014, 9, e113409.

24. Chen, H.; Zhao, X.; Han, Y.; Xing, F.; Feng, L.; Wang, Z.; Wang, G.; Yang, B.; Lei, Y.; Xiong, S.; et al. Competition for light interception in cotton populations of different densities. Agronomy 2021, 11, 176. [CrossRef]

25. Khan, N.; Han, Y.; Xing, F.; Feng, L.; Wang, Z.; Wang, G.; Yang, B.; Fan, Z.; Lei, Y.; Xiong, S.; et al. Plant density influences reproductive growth, lint yield and boll spatial distribution of cotton. Agronomy 2019, 10, 14. [CrossRef]

26. Yao, H.; Zhang, Y.; Yi, X.; Zhang, X.; Zhang, W. Cotton responds to different plant population densities by adjusting specific leaf area to optimize canopy photosynthetic use efficiency of light and nitrogen. Field Crop. Res. 2016, 188, 10-16. [CrossRef]

27. Zhang, D.; Zhang, L.; Liu, J.; Han, S.; Wang, Q.; Evers, J.; Liu, J.; Werf, W.; Li, L. Plant density affects light interception and yield in cotton grown as companion crop in young jujube plantations. Field Crop. Res. 2014, 169, 132-139. [CrossRef]

28. Zhang, L.; Werf, W.; Bastiaans, L.; Zhang, S.; Li, B.; Spiertz, J.H. Light interception and utilization in relay intercrops of wheat and cotton. Field Crop. Res. 2008, 107, 29-42. [CrossRef]

29. Zhi, X.; Han, Y.; Xing, F.; Lei, Y.; Wang, G.; Feng, L.; Yang, B.; Wang, Z.; Li, X.; Xiong, S. How do cotton light interception and carbohydrate partitioning respond to cropping systems including monoculture, intercropping with wheat, and direct-seeding after wheat? PLoS ONE 2019, 14, e0217243. [CrossRef]

30. Han, H.; Deng, F.; Li, B.; Yang, B.; Yang, L.; Lin, H.; Wang, X. Effect of sowing density on the yield and quality of high-yield cotton in Xinjiang. Jiangsu Agric. Sci. 2009, 37, 98-100.

31. Weiner, J.; Du, Y.; Zhang, C.; Qin, X.; Li, F. Evolutionary agroecology: Individual fitness and population yield in wheat (Triticum aestivum). Ecology 2017, 98, 2261-2266. [CrossRef]

32. Mao, L.; Zhang, L.; Evers, J.B.; Werf, W.; Liu, S.; Zhang, S.; Wang, B.; Li, Z. Yield components and quality of intercropped cotton in response to mepiquat chloride and plant density. Field Crop. Res. 2015, 179, 63-71. [CrossRef]

33. Flénet, D.; Mollier, A.; Pellerin, S. Growth analysis of maize field crops under phosphorus deficiency. II. Radiation-use efficiency, biomass accumulation and yield components. Plant Soil 2000, 224, 259-272.

34. Robinson, K.M.; Karp, A.; Taylor, G. Defining leaf traits linked to yield in short-rotation coppice Salix. Biomass Bioenerg. 2004, 26, 417-431. [CrossRef] 
35. Houx, J.H.; Fritschi, F.B. Influence of late planting on light interception, radiation use efficiency and biomass production of four sweet sorghum cultivars. Ind. Crop. Prod. 2015, 76, 62-68. [CrossRef]

36. Su, B.; Song, Y.; Chen, S.; Yang, W. Photosynthetic responses of soybean (Glycine max) seedlings to shading caused by maize in an intercropping system. Acta Ecol. Sin. 2015, 35, 3298-3308.

37. Francescangeli, N.; Sangiacomo, M.A.; Martí, H. Effects of plant density in broccoli on yield and radiation use efficiency. Sci. Hortic. 2006, 110, 135-143. [CrossRef]

38. Lu, J.; Liu, K.; Deng, J.; Feng, X.; Xiong, X.; Huang, L.; Tian, X.; Zhang, Y. Evaluating the effect of population density and the contribution of early canopy closure to grain yield of hybrid rice. J. Plant Growth Regul. 2021, 1-10, (online first). [CrossRef]

39. Mercado, L.M.; Bollouin, N.; Sitch, S.; Boucher, O.; Huntingford, C.; Wild, M.; Cox, P.M. Impact of changes in diffuse radiation on the global land carbon sink. Nature 2009, 458, 1014-1017. [CrossRef]

40. Sun, J.; Liu, S.; Hu, Q.; Bai, Z.; Cui, A. The Influence of Different Planting Density on the Spatial Distribution of Cotton Boll. Cotton Sci. 2021, 43, 31-36.

41. Zhu, X.; Liu, L.; Wan, H.; Zhang, Y.; Sun, H.; Li, C. Effects of pruning methods and canopy patterns on the temporal-spatial distribution of cotton bolls and yield. Cotton Sci 2019, 31, 79-88.

42. Xue, H.; Han, Y.; Li, Y.; Wang, G.; Feng, L.; Fan, Z.; Du, W.; Yang, B.; Cao, C.; Mao, S. Spatial distribution of light interception by different plant population densities and its relationship with yield. Field Crop. Res. 2015, 184, 17-27. [CrossRef]

43. Khan, N.; Xing, F.; Feng, L.; Wang, Z.; Xin, M.; Xiong, S.; Wang, G.; Chen, H.; Du, W.; Li, Y. Comparative yield, fiber quality and dry matter production of cotton planted at various densities under equidistant row arrangement. Agronomy 2020, 10, 232. [CrossRef]

44. Li, Q. The diaphragm cotton bud is now shedding regular tile bud book with bell measures. Xinjiang Farm Res. Sci. Technol. 2005, 10-11.

45. Mattera, J.; Romero, L.A.; Cuatrín, A.L.; Cornaglia, P.S.; Grimoldi, A.A. Yield components, light interception and radiation use efficiency of lucerne (Medicago sativa L.) in response to row spacing. Eur. J. Agron. 2013, 45, 87-95. [CrossRef]

46. Kaggwa-Asiimwe, R.; Andrade-Sanchez, P.; Wang, G. Plant architecture influences growth and yield response of upland cotton to population density. Field Crop. Res. 2013, 145, 52-59. [CrossRef] 